\title{
Enhancement of corrosion resistance and mechanical properties of API 5L X60 steel by heat treatments in different environments
}

\author{
Haider Mahdi Lieth, Raheem Al-Sabur*, Raad Jamal Jassim and Ahmad Alsahlani \\ Department of Mechanic, Engineering College, University of Basrah, Basrah, Iraq \\ *Corresponding Author : raheem.musawel@uobasrah.edu.iq
}

Submitted :22/06/2021

Revised :21/08/2021

Accepted :01/09/2021

\begin{abstract}
Steel pipelines are commonly used in the petroleum industry, where high strength and durability values are required. In oil installations, the problems of corrosion, especially with crude oil, appear clearly and dramatically in dealing with API 5L series. Improving the corrosion protection and mechanical properties is a genius goal for steel manufacturers, and the heat treatment processes are familiar in this field. In this study, experimental investigations were executed to find the heat treatment influence on the corrosion rate, microstructure, and mechanical properties behavior of API 5L X60 pipeline steel in the presence of three different environments: seawater, freshwater, and crude oil. Two austenitizing temperatures, $900^{\circ} \mathrm{C}$ and $800^{\circ} \mathrm{C}$, were prepared, followed by quenching at $600^{\circ} \mathrm{C}$, $450^{\circ} \mathrm{C}$, and $300^{\circ} \mathrm{C}$, respectively, where the corrosion rate was estimated by the mean weight loss method. In this study, more than $60 \%$ of the corrosion rate in both seawater and freshwater was improved at $900{ }^{\circ} \mathrm{C}$, austenitizing tempered at $300^{\circ} \mathrm{C}$, for the selected pipeline specimens, while only $22 \%$ reduction was achieved in crude oil. Different microstructure phases appeared in the heat-treated specimens such as tempered martensitic at $300^{\circ} \mathrm{C}$ and fine-grained ferrite with polygonal ferrite at $600^{\circ} \mathrm{C}$. The microhardness values decreased with increasing the tempering temperatures, while impact toughness values increased with tempering temperature increasing from $300^{\circ} \mathrm{C}$ until it reached $450^{\circ} \mathrm{C}$ and then returned to decrease again in $600^{\circ} \mathrm{C}$.
\end{abstract}

Keywords: Heat treatment; Corrosion rate; Weight losses; API 5L; Microstructure; Mechanical properties.

\section{INTRODUCTION}

The damaging influence of the surrounding environment on materials is called corrosion, which is considered a natural phenomenon. Galvanic attack, universal attack, selective parting, pitting, and erosion are considered to be the commonly adopted corrosion classifications (Kuruvila et al. 2018). Oil and gas are key contributors to energy supply, and pipelines are the principal way of transporting them (Boye and Samuel 2020). In pipeline material selection, the availability of information on its operating environment and other pertinent variables, such as water content, gases, pressure, and temperature, flow rate, $\mathrm{pH}$, and design, is necessary. Carbon steel is preferred in industrial pipelines, because it is readily available, is durable, and has suitable mechanical properties (Moosavi 2017). Microbiologically influenced corrosion, sweet corrosion, and sour corrosion are the major problems in steel pipelines, especially API 
5L series (Popoola et al. 2013; Yadav and Sharma 2011). The combination of water with H2S and CO2 gases is the main cause of corrosion in oil and gas pipelines (Rajeev, Surendranathan, and Murthy 2012; Rustandi et al. 2012).

In the last two decades, with the widespread use of enhanced oil recovery (EOR) methods, as well as the great development of oil recovery methods, the produced substances have become generally more corrosive to carbon steel. A variety of organic compounds and hydrocarbons, as well as some specific salt solution extract from crude oil, have a big role in the steel corrosion (Wang and Zhang 2016). Existing crude oil can influence the specifications of the wear quantities of the product. The crude oil's ability to wet the corroded carbon steel surface is well known as wettability preference (Farelas et al. 2013).

Most studies have dealt with different corrosion environments, such as freshwater, seawater, and $\mathrm{NaCl}$ for API $5 \mathrm{~L}$ series. For $\mathrm{pH}$ value under turbulent flow conditions, the results showed that the corrosion mechanism was mainly controlled by mass transport at $\mathrm{pH}=4$ (Rustandi et al. 2013). In addition, different $\mathrm{pH}$ values and concentrations of various exposed solutions affect the corrosion

behavior of heat-treated samples (Sharma and Chhibber 2019). Hamed et al. conducted a comparative study between theoretical chemical parameters and experimental inhibition efficiency of Gemini surfactants for carbon steel API 5L X52 grade (Hamed et al. 2019).

\section{HEAT TREATMENTS}

Heat treatment is a specific operation that depends on heating, soaking, and cooling selective temperature rates and time rates to achieve a predetermined property and obtain the desired microstructure (Tanzi, Farè, and Candiani 2019). The main reason of using heat treatment for the carbon steel is to enhance the mechanical properties, such as hardness, ductility, yield strength, impact resistance, tensile strength, and corrosion, which can be manipulated. Throughout the heat treatment, the metal generally suffers phase microstructural and crystallographic changes (Daramola, Adewuyi, and Oladele 2010). The microstructure of austenitizing and tempered API 5L X60 pipe consists of bainite, tempered martensite, and sediment. Their corrosion rates are considerably higher than those of the steels of ferrite and pearlite microstructure. Suitable heat treatments can be used to obtain API steel pipelines, thereby leading to increased fracture toughness and tensile mechanical properties (Godefroid, Sena, and Trindade Filho 2017). Postheating treatment of API 5L X65 pipeline can lead to improvement of adhesive strength (Thiangpak and Rodchanarowan 2018). Quasipolygonal ferrite microstructure can appear, which can severely reduce yield strength and improve plasticity (Jing et al. 2009). Adnan et al. showed that the quenched specimens appeared to corrode more in carbon dioxide CO2 and acetic acid media than in annealed specimens (Adnan et al. 2018). The corrosion resistance can be effective up to $96.67 \%$ when using an amine-based organic inhibitor (Swandito and Malau 2020).

\section{CORROSION RATE CALCULATION}

Several techniques can be used to calculate corrosion rates, such as electrochemical impedance spectroscopy (EIS), electrochemical linear polarization resistance (LPR), and weight loss technique (Mohammed Nor et al. 2014; Souza et al. 2016; Ji and Tong 2014; Sun et al. 2018). The weight loss technique is considered the easiest and simplest method (Ji and Tong 2014; Sun et al. 2018). It is a simple method performed by exposing a material specimen to a process environment for a given duration, then removing it for analysis according to ASTM G31. It depends on the accurate balance, where the results were utilized to determine the materials' relative corrosiveness (Pearson and Cousins 2016). The rate of corrosion is measured using the following relation (Standard 2004):

$$
C R=\frac{\Delta m \times 24 \times 365 \times 10}{\rho \times A \times t}
$$


where $\Delta \mathrm{m}$ is the weight loss $(\mathrm{g})$, A is the exposed surface area $\left(\mathrm{cm}^{2}\right)$, and $\rho$ is the metal density $\left(\mathrm{g} / \mathrm{cm}^{3}\right)$; it is the period of immersion (h).

We attempt to investigate the influence of heat treatment on the corrosion rate and the mechanical properties in API X60 steel pipelines used in the Iraqi petroleum industry. These specimens were annealed (austenitized), quenched, and then tempered at different temperatures independently. Corrosion rates were measured employing weight loss.

\section{MATERIALS AND METHODS}

Spectrum analyzer (SPECTROTEST TXC25) is used for the chemical composition of the API X60, as shown in Table 1.

Table 1. Chemical composition of API X60 steel (wt\%).

\begin{tabular}{|c|c|c|c|c|c|cc|c|}
\hline Base metal & $\mathbf{C}$ & Si & Mn & Cr & Mo & Ni & Cu & Fe \\
\hline$\%$ & 0.141 & 0.216 & 0.97 & 0.112 & 0.023 & 0.09 & 0.266 & Bal. \\
\hline
\end{tabular}

A CNC machine was used to prepare a lot of API X60 specimens $(10 \times 10 \times 55 \mathrm{~mm})$ from a pipeline. Accurate digital precision balance was used for specimen's weight measuring to select the best 63 specimens of weight $43 \mathrm{~g}$. The 63 specimens were divided into two divisions: 54 heat-treated specimens and 9 specimens without heat treatment. Later, all specimens were also subdivided into 21 groups, with each group having 3 specimens according to the heat treatment and immersion media environments as shown in table 2.

Table 1. Specimens divisions according to heat treatment and immersion media.

\begin{tabular}{|c|c|c|c|c|}
\hline Group & $\begin{array}{c}\text { Austenitizing } \\
\text { Temperature }\end{array}$ & $\begin{array}{c}\text { Tempering } \\
\text { Temperature }\end{array}$ & Period & Media \\
\hline 1 & $900^{\circ} \mathrm{C}$ & $600^{\circ} \mathrm{C}$ & $1 \mathrm{hr}$ & Crude Oil \\
\hline 2 & $900^{\circ} \mathrm{C}$ & $600{ }^{\circ} \mathrm{C}$ & $1 \mathrm{hr}$ & Seawater \\
\hline 3 & $900^{\circ} \mathrm{C}$ & $600{ }^{\circ} \mathrm{C}$ & $1 \mathrm{hr}$ & Freshwater \\
\hline 4 & $900^{\circ} \mathrm{C}$ & $450{ }^{\circ} \mathrm{C}$ & $1 \mathrm{hr}$ & Crude Oil \\
\hline 5 & $900^{\circ} \mathrm{C}$ & $450{ }^{\circ} \mathrm{C}$ & $1 \mathrm{hr}$ & Seawater \\
\hline 6 & $900^{\circ} \mathrm{C}$ & $450{ }^{\circ} \mathrm{C}$ & $1 \mathrm{hr}$ & Freshwater \\
\hline 7 & $900^{\circ} \mathrm{C}$ & $300^{\circ} \mathrm{C}$ & $1 \mathrm{hr}$ & Crude Oil \\
\hline 8 & $900^{\circ} \mathrm{C}$ & $300^{\circ} \mathrm{C}$ & $1 \mathrm{hr}$ & Seawater \\
\hline 9 & $900^{\circ} \mathrm{C}$ & $300^{\circ} \mathrm{C}$ & $1 \mathrm{hr}$ & Freshwater \\
\hline 10 & $800^{\circ} \mathrm{C}$ & $600^{\circ} \mathrm{C}$ & $1 \mathrm{hr}$ & Crude Oil \\
\hline 11 & $800^{\circ} \mathrm{C}$ & $600^{\circ} \mathrm{C}$ & $1 \mathrm{hr}$ & Seawater \\
\hline 12 & $800^{\circ} \mathrm{C}$ & $600^{\circ} \mathrm{C}$ & $1 \mathrm{hr}$ & Freshwater \\
\hline 13 & $800^{\circ} \mathrm{C}$ & $450^{\circ} \mathrm{C}$ & $1 \mathrm{hr}$ & Crude Oil \\
\hline
\end{tabular}




\begin{tabular}{|c|c|c|c|c|}
\hline 14 & $800{ }^{\circ} \mathrm{C}$ & $450{ }^{\circ} \mathrm{C}$ & $1 \mathrm{hr}$ & Seawater \\
\hline 15 & $800^{\circ} \mathrm{C}$ & $450^{\circ} \mathrm{C}$ & $1 \mathrm{hr}$ & Freshwater \\
\hline 16 & $800^{\circ} \mathrm{C}$ & $300^{\circ} \mathrm{C}$ & $1 \mathrm{hr}$ & Crude Oil \\
\hline 17 & $800^{\circ} \mathrm{C}$ & $300^{\circ} \mathrm{C}$ & $1 \mathrm{hr}$ & Seawater \\
\hline 18 & $800^{\circ} \mathrm{C}$ & $300^{\circ} \mathrm{C}$ & $1 \mathrm{hr}$ & Freshwater \\
\hline 19 & \multicolumn{3}{|c|}{ Without Heat Treatment } & Crude Oil \\
\hline 20 & \multicolumn{3}{|c|}{ Without Heat Treatment } & Freshwater \\
\hline 21 & \multicolumn{3}{|c}{} \\
\hline
\end{tabular}

All heat-treated specimens were polished and grinded according to ASTM E3 (ASTM 2001) with emery cloth roll and grit papers of 80-600 of 4-inch-wide sandpaper. To reduce the phenomena of crevice corrosion, each specimen was hung to a glass rod inside an incubator (Liptakova, Fajnor et al. 2014). The specimens hanging are shown in Figure 1. All 63 specimens were immersed in three different environments for 42 days, freshwater $(\mathrm{pH}=$ 9.5), seawater ( $\mathrm{pH}=8.13)$, and crude oil $(\mathrm{pH}=6.5)$, as shown in table 1 . The specimens were cleaned with acetone and reverse osmosis (RO) water using brushes. Finally, the samples were air-dried before weight measurement every two weeks. Cleaning involves preparing the specimen surface by removing the corrosion products by dissolution in an etching solution (Nital 2\%) for $30 \mathrm{~s}$, according to the ASTM E407-07 (E407-07 2015).

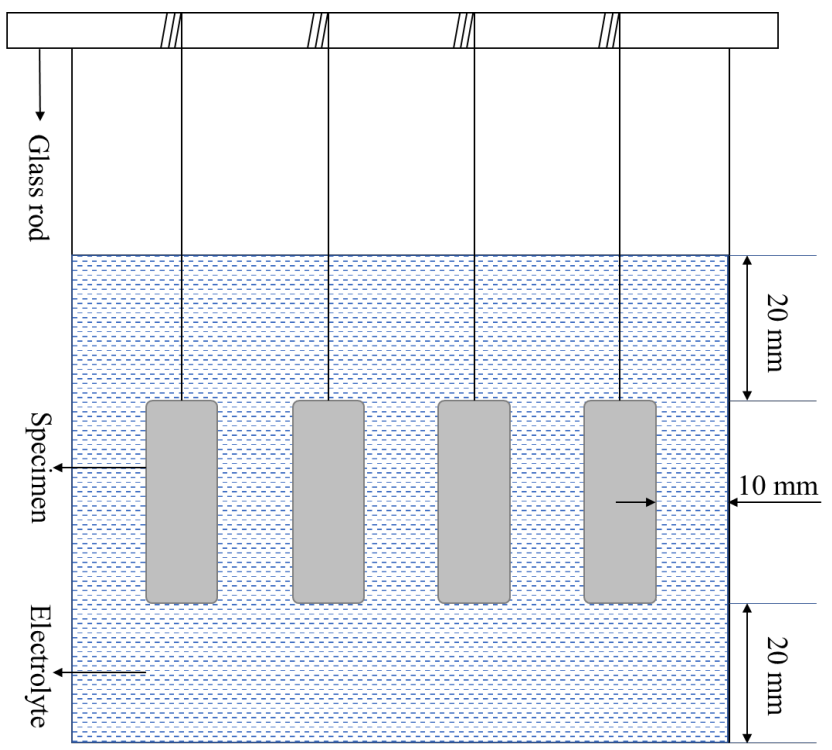

Figure 1. Schematic of the immersion test apparatus inside incubator.

\section{RESULTS AND DISCUSSIONS}

\section{1- Corrosion Rates}

In this section, the mass difference caused by corrosive phenomena is defined with respect to the surface of the samples. It is obvious that, for all specimen's corrosion test, the change in the mass is a function of time. Mass loss method provides a straightforward manner to calculate the corrosion rates. Equation 1 was used for calculating the corrosion rate by measuring the weight of the intact sample material before and after the corrosion process (after corrosion product removal). 
Table 3 shows the average corrosion rate and average mass weight at $900{ }^{\circ} \mathrm{C}$ austenitizing (groups $1-9$ ), Table 4 at $800{ }^{\circ} \mathrm{C}$ austenitizing (groups 10-18), and Table 5 without any heat treatment (groups 19-21). The mass loss weights increase with increasing specimen immersion period in each environment, even with or without tempering. In most specimens used, the weight losses in the crude oil environment are lower than those in the seawater environment, which, in turn, are greater than that in the freshwater environment with the increase in immersion period.

Table 3. The corrosion rate and specimens' weights changing at $900{ }^{\circ} \mathrm{C}$ austenitizing.

\begin{tabular}{|c|c|c|c|c|c|c|c|}
\hline \multirow{2}{*}{ Groups } & \multirow{2}{*}{$\mathbf{T}\left({ }^{\circ} \mathbf{C}\right)$} & \multirow{2}{*}{ Media } & \multicolumn{4}{|c|}{ Weights (g) } & \multirow{2}{*}{$\begin{array}{c}\text { CR } \\
(\mathrm{MM} / \mathrm{Y})\end{array}$} \\
\hline & & & original & 2 weeks & 3 weeks & 4 weeks & \\
\hline 1 & \multirow{3}{*}{$600^{\circ} \mathrm{C}$} & Crude oil & 43 & 42.922 & 42.859 & 42.779 & 0.1022 \\
\hline 2 & & Seawater & 43 & 42.983 & 42.911 & 42.859 & 0.0652 \\
\hline 3 & & Freshwater & 43 & 42.979 & 42.964 & 42.952 & 0.0222 \\
\hline 4 & \multirow{3}{*}{$450^{\circ} \mathrm{C}$} & Crude oil & 43 & 42.998 & 42.952 & 42.941 & 0.0273 \\
\hline 5 & & Seawater & 43 & 42.932 & 42.905 & 42.882 & 0.0546 \\
\hline 6 & & Freshwater & 43 & 42.961 & 42.934 & 42.921 & 0.0366 \\
\hline 7 & \multirow{3}{*}{$300^{\circ} \mathrm{C}$} & Crude oil & 43 & 42.984 & 42.966 & 42.952 & 0.0222 \\
\hline 8 & & Seawater & 43 & 42.974 & 42.96 & 42.945 & 0.0254 \\
\hline 9 & & Freshwater & 43 & 42.991 & 42.983 & 42.965 & 0.0162 \\
\hline
\end{tabular}

Table 4. The corrosion rate and specimens' weights changing at $800{ }^{\circ} \mathrm{C}$ austenitizing.

\begin{tabular}{|c|c|c|c|c|c|c|c|}
\hline \multirow{2}{*}{ Groups } & \multirow{2}{*}{$\mathbf{T}\left({ }^{\circ} \mathbf{C}\right)$} & \multirow{2}{*}{ Media } & \multicolumn{4}{|c|}{ Weights (g) } & \multirow{2}{*}{$\begin{array}{c}\text { CR } \\
(\mathbf{M M} / \mathbf{Y})\end{array}$} \\
\hline & & & original & 2 weeks & 3 weeks & 4 weeks & \\
\hline 10 & \multirow{3}{*}{$600^{\circ} \mathrm{C}$} & Crude oil & 43 & 42.949 & 42.939 & 42.937 & 0.0291 \\
\hline 11 & & Seawater & 43 & 42.803 & 42.748 & 42.728 & 0.1258 \\
\hline 12 & & Freshwater & 43 & 42.975 & 42.952 & 42.933 & 0.0310 \\
\hline 13 & \multirow{3}{*}{$450^{\circ} \mathrm{C}$} & Crude oil & 43 & 42.996 & 42.978 & 42.973 & 0.0125 \\
\hline 14 & & Seawater & 43 & 42.972 & 42.952 & 42.937 & 0.0291 \\
\hline 15 & & Freshwater & 43 & 42.97 & 42.955 & 42.937 & 0.0291 \\
\hline 16 & \multirow{3}{*}{$300^{\circ} \mathrm{C}$} & Crude oil & 43 & 42.997 & 42.991 & 42.986 & 0.0065 \\
\hline 17 & & Seawater & 43 & 42.961 & 42.932 & 42.913 & 0.0403 \\
\hline 18 & & Freshwater & 43 & 42.949 & 42.926 & 42.907 & 0.0430 \\
\hline
\end{tabular}


Table 5. Corrosion rate and mass weight without treatment at different environments.

\begin{tabular}{|c|c|c|c|c|c|c|c|}
\hline \multirow{2}{*}{ Groups } & \multirow{2}{*}{$\mathbf{T}\left({ }^{\circ} \mathbf{C}\right)$} & \multirow{2}{*}{ Media } & \multicolumn{4}{|c|}{ Weights (g) } & \multirow{2}{*}{$\begin{array}{c}\text { CR } \\
(\mathbf{M M} / \mathbf{Y})\end{array}$} \\
\hline & & & original & 2 weeks & 3 weeks & 4 weeks & \\
\hline 19 & \multirow{3}{*}{$\begin{array}{l}\text { Without } \\
\text { Treatment }\end{array}$} & Crude oil & 43 & 42.994 & 42.984 & 42.982 & 0.0083 \\
\hline 20 & & Seawater & 43 & 42.923 & 42.896 & 42.862 & 0.0638 \\
\hline 21 & & Freshwater & 43 & 42.951 & 42.933 & 42.905 & 0.0440 \\
\hline
\end{tabular}

The total weight losses, which represent the differences between the final and initial weights for each specimen after 42 days, are shown in Figure 2. For the seawater and freshwater environments, the minimum weight losses were achieved at austenitizing temperatures of $900{ }^{\circ} \mathrm{C}$ and quenching tempering of $300^{\circ} \mathrm{C}$. In crude oil, the best conditions were obtained at $\left(800^{\circ} \mathrm{C}\right)$ austenitizing and $\left(300^{\circ} \mathrm{C}\right)$ quenching tempering.

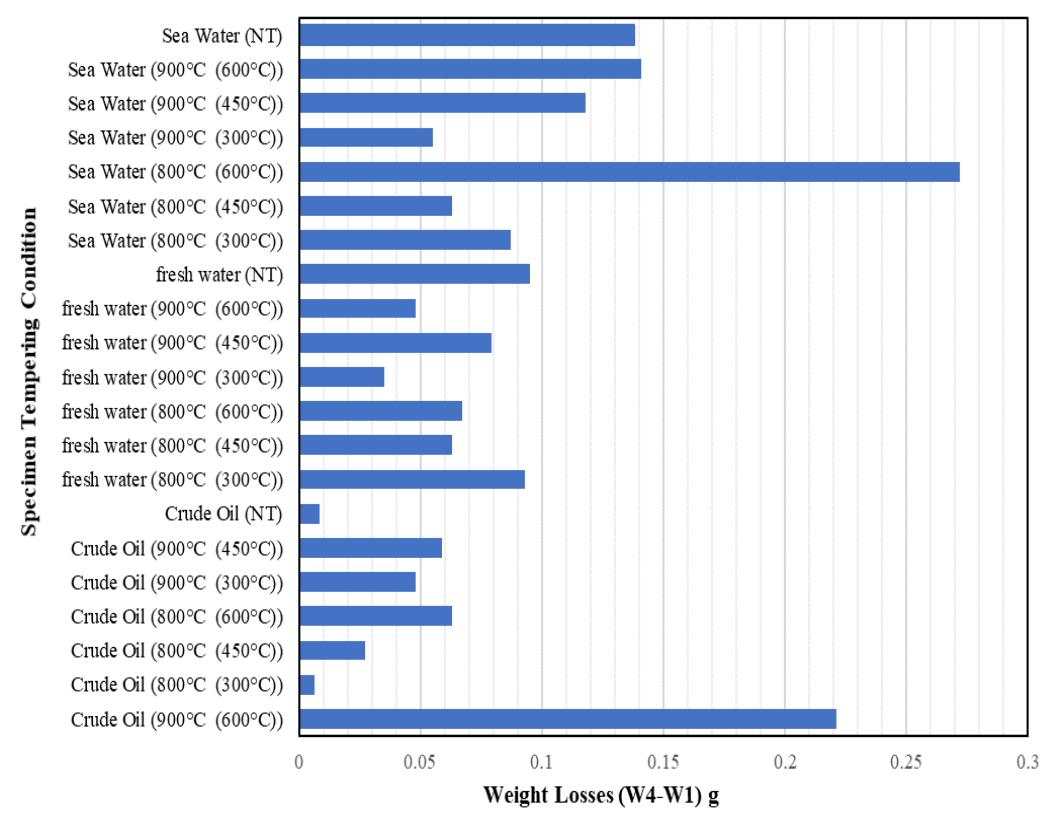

Figure 2. Weight losses of all the tested specimens at different conditions.

Without heat treatment, the specimens in seawater obtained higher corrosion rates $(0.063 \mathrm{~mm} / \mathrm{y})$ than those in freshwater $(0.044 \mathrm{~mm} / \mathrm{y})$ and crude oil $(0.008 \mathrm{~mm} / \mathrm{y})$. The applied heat treatments successfully modified the metallurgy of metal, thereby developing the surface reactivity. A $63 \%$ reduction in corrosion rate occurred in group 9 at $900{ }^{\circ} \mathrm{C}$ austenitizing with $300^{\circ} \mathrm{C}$ tempering (red color) compared with non-heat-treated specimens (grey color) in the freshwater environment, as shown in Figure 3-a. In seawater specimens, a $60 \%$ reduction in corrosion rate occurred in group 8 at $900{ }^{\circ} \mathrm{C}$ austenitizing with $300{ }^{\circ} \mathrm{C}$ tempering (red color) compared with non-heat-treated, as shown in Figure 3-b. 

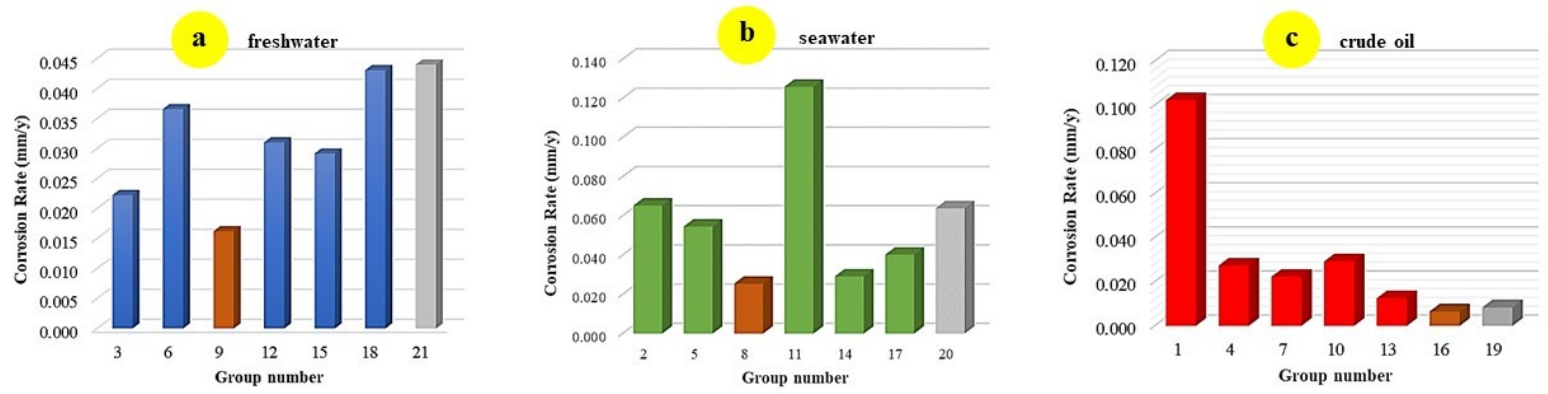

Figure 3. Corrosion rates of specimens in a) fresh water, b) sea water, and c) crude oil.

In terms of crude oil, the heat treatment process was insufficient in most specimens except in group 16 at 800 ${ }^{\circ} \mathrm{C}$ austenitizing with $300{ }^{\circ} \mathrm{C}$ tempering with a corrosion rate reduction of $22 \%$, as shown in Figure 3 -c. This behavior can be explained by two reasons. First, the $\mathrm{pH}$ value is 6.5 ; thus, the medium encourages the increase in corrosion rate. Second, soft-tempered martensite is obtained from heat treatment (austenitizing $900{ }^{\circ} \mathrm{C}$; tempering $300{ }^{\circ} \mathrm{C}$ ).

\section{2- Microhardness}

The microhardness values were calculated directly after the six-week test at room temperature. As a result, all the microstructural changes occurred due to heat treatments. When the tempering temperature is fixed at $300{ }^{\circ} \mathrm{C}$, and the austenitizing temperature was $900{ }^{\circ} \mathrm{C}$, the hardness values increase with the change in the corrosive medium from freshwater, seawater, and finally crude oil. The hardness values decrease by increasing the tempering temperature and by maintaining the austenitizing temperature at $900{ }^{\circ} \mathrm{C}$. The results extracted from the study were compared with those in (Sharma and Chhibber 2019). The hardness values of crude oil as a corrosive medium were maintained at highest, followed by the values of seawater and finally freshwater without a noticeable behavior change, as shown in Figure 4-a. This finding indicates that the best hardness values can be obtained when using crude oil as a corrosive medium. In general, the hardness of medium carbon steel after tempering is lower than that of the sample after quenching (Ismail et al. 2016).
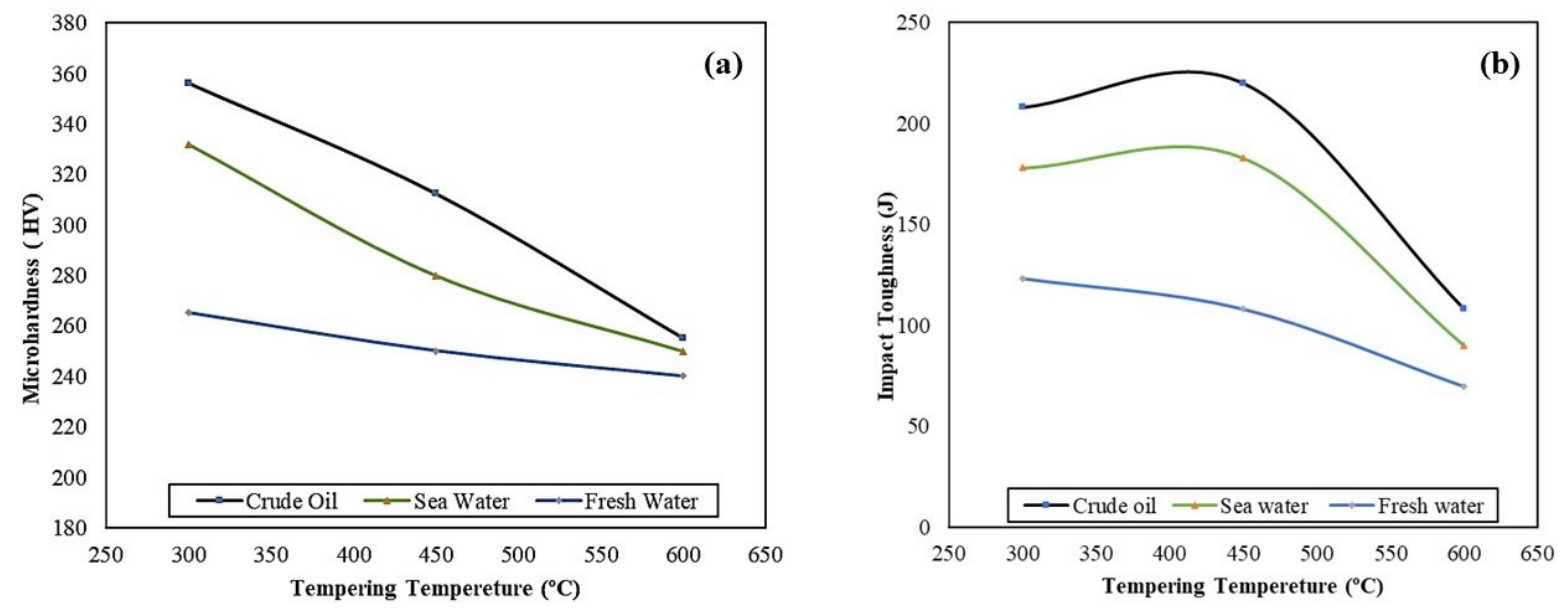

Figure 4. Relation between a) microhardness and b) impact toughness with tempering temperature at $900^{\circ} \mathrm{C}$ Austenitizing. 


\section{3- Impact Hardness}

The results showed that the impact toughness gradually increases with increasing tempering temperature up to $450{ }^{\circ} \mathrm{C}$, and the toughness curve begins to fall. The flake carbides are unevenly distributed on the original martensite boundaries, and the Charpy absorbed energy is 230, 190, and $128 \mathrm{~J}$ for crude oil, seawater, and freshwater, respectively, as shown in Figure 4-b. The values of impact toughness are inferred from the study and from Sharma and Chhibber (2019). The impact toughness absorbed energy is reduced notably when the tempering temperature is $600{ }^{\circ} \mathrm{C}$; the coarsened granular carbides appear evidently in the formed microstructure; the key factor of toughness affects the API X60 alloy (Chen and LU 2012).

\section{4- Microstructure Evolution}

The phases that appear in microstructure examination are mainly ferrite with fine grain pearlite, as shown in Figure 5-a, after austenitizing heat treatment and tempering in different temperatures of $600{ }^{\circ} \mathrm{C}, 450{ }^{\circ} \mathrm{C}$, and $300{ }^{\circ} \mathrm{C}$. The predominant phase is tempered martensite. The efficiency of heat treatment can be improved by tempering after quenching. The ability of ferrite for corrosion resistance is better than that of the tempered martensite, but the presence of the pearlite phase indicates that the medium is less resistant to corrosion, due to the possibility that one of the phases is a cathode, and the other is an anode. The microstructure of metal after heat treatments is shown in Figures $5 \mathrm{~b}-\mathrm{d}$ in crude oil environments. The content, shape, distribution, and size of the tempered martensite are directly related to tempering temperature.

Figure 6 explains the microstructure of metal after austenitizing at $900{ }^{\circ} \mathrm{C}$ and tempered at $450{ }^{\circ} \mathrm{C}$ in different environments (as-received, crude oil, freshwater, and seawater). The figure also shows the difference in microstructure by changing the environments into noneffective, holistic, and dependent on tempering temperature. The main influencing factor on the internal microstructure of the samples indicates that the change in tempering temperature and mechanical properties directly influences the corrosion resistance. As a comparative study for steel alloys, in the hydrogen sulfide medium, the corrosion rate tends to increase in an aqueous environment with decreasing pH value (Li, Wang, and Zhang 1993; Ma et al. 2000).

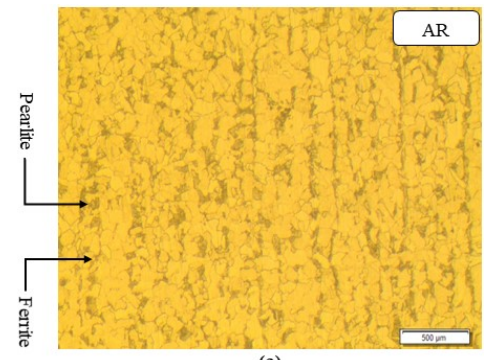

(a)

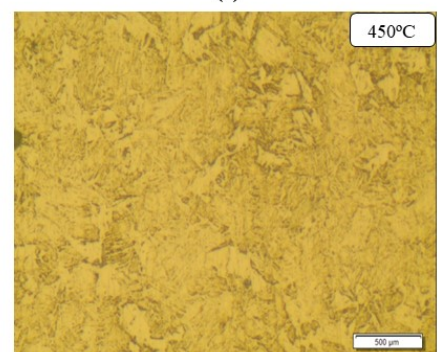

(c)

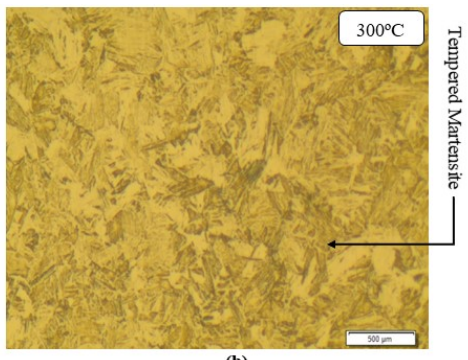

(b)

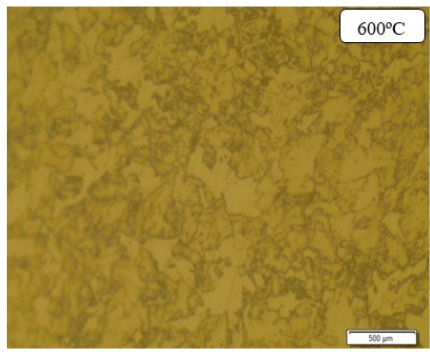

(d)

Figure 5. Microstructure examination of API X60 austenitizing $900^{\circ} \mathrm{C}$ in crude oil: (a) as-received steel (AR),

(b) quenched at $300{ }^{\circ} \mathrm{C}$, (c) quenched at $450{ }^{\circ} \mathrm{C}$, and (d) quenched at $600{ }^{\circ} \mathrm{C}$. 


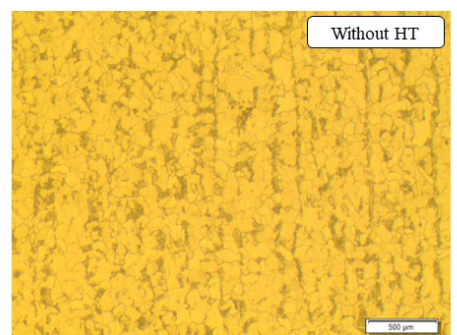

(a)

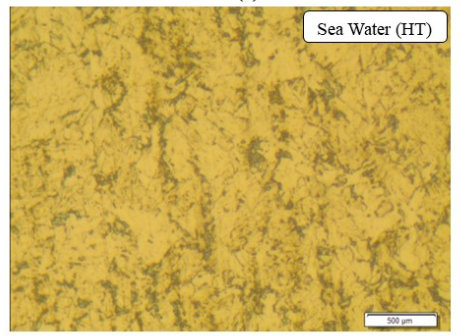

(c)

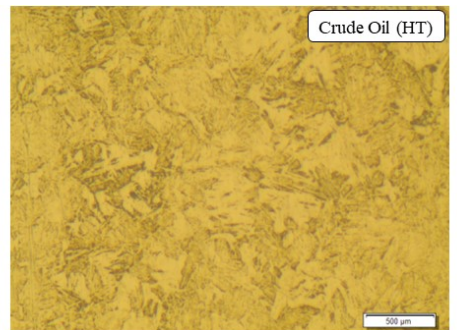

(b)

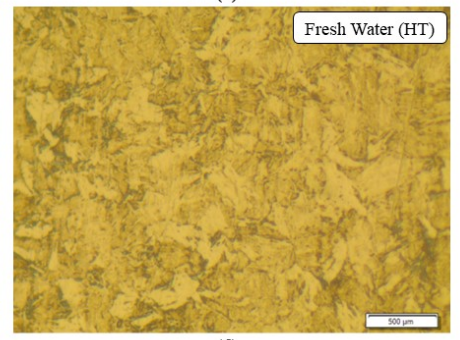

(d)

Figure 6. Microstructure examination of API X60 austenitizing $900^{\circ} \mathrm{C}$ : (a) as-received steel (AR), (b) crude oil, (c) sea water, and (d) fresh water.

\section{5-Surfaces Analysis}

Images of corrosion surfaces were recorded in a scanning electron microscope model NOVA NANOSEM 450. Figure 7 depicts the variation seen in polished surface morphology for as-received steel (Figure 7-a) and austenitizing $900^{\circ} \mathrm{C}$, tempered temperature $300^{\circ} \mathrm{C}, 450{ }^{\circ} \mathrm{C}$, and $600^{\circ} \mathrm{C}$, respectively, crude oil (Figure 7-b-d). Surface micrographs were obtained by SEM. Figure 7-b demonstrates the specimen, which was lower-corroded, hard, and rough. Because of the slow aggressive corrosion treatment, the steel surface was a little damaged in the presence of heat treatment.
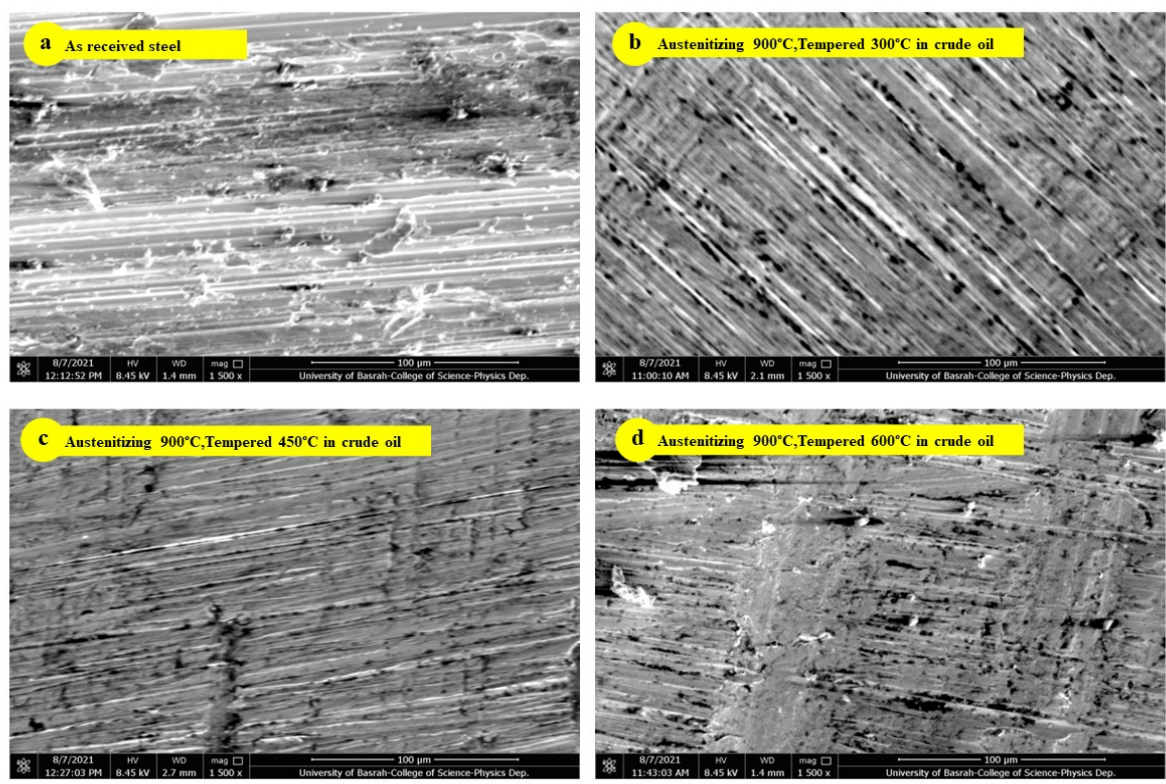

Figure 7. SEM images for API 5L X60 steel at different heat treatment conditions in crude oil. 
Figure 8 explains the polished sample morphology for as-received steel, austenitizing $900{ }^{\circ} \mathrm{C}$, tempered at $300 \mathrm{oC}$, crude oil, sea, and freshwater, respectively, (Figure 8-a-d) with a magnification of $3500 \mathrm{X}$. The images of the electronic scanner show that the nature of the surface for crude oil is more affected compared to seawater and freshwater because of the products of the corrosion process on the surface. Crude oil affects the corrosion of steel in the production of crude oil, as the crude oil changes the chemistry of the brine, which affects the corrosion rate, as well as the protection of corrosion product layer created on the steel.
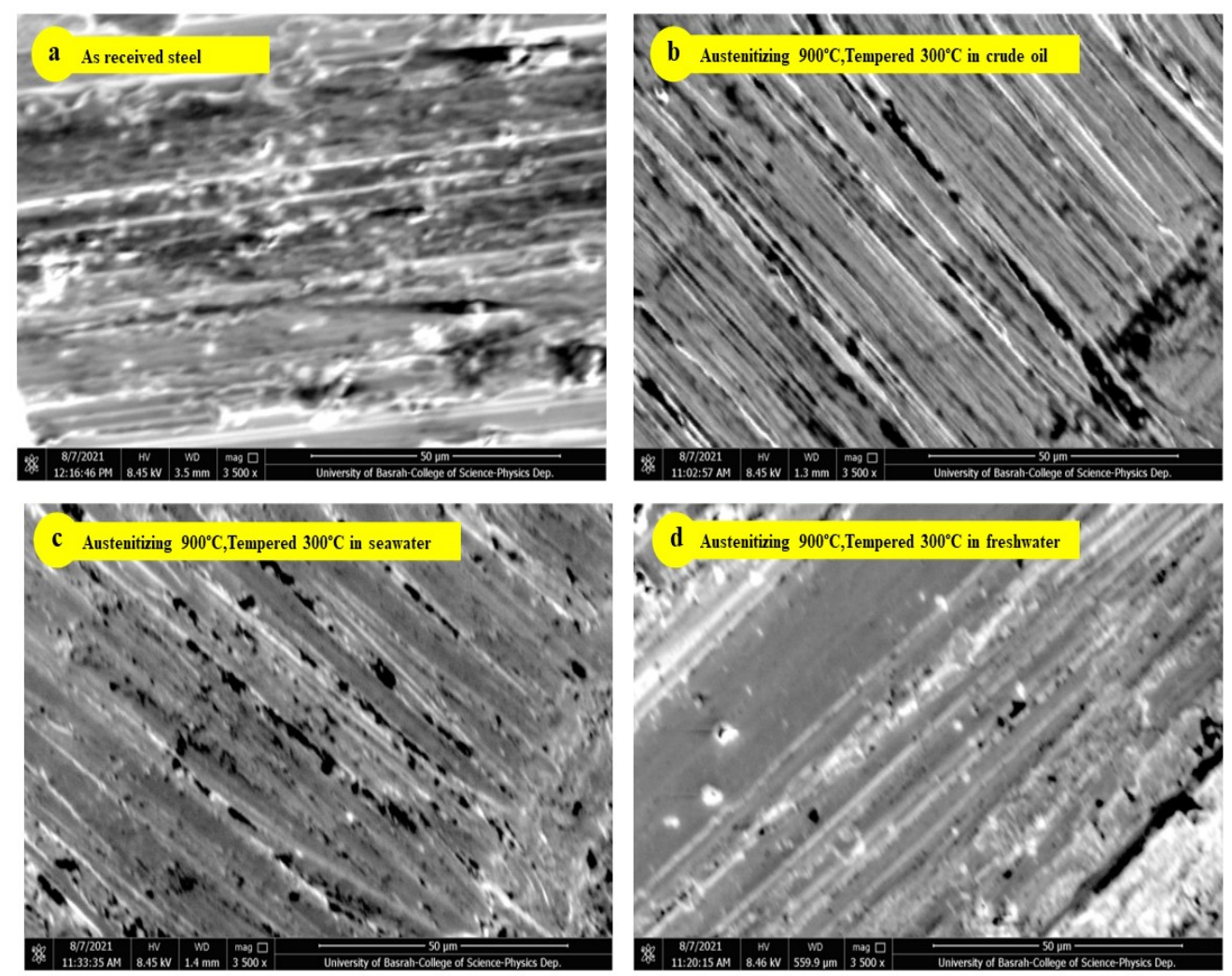

Figure 8. SEM images for API 5L X60 steel at austenitizing $900^{\circ} \mathrm{C}$, tempered $300^{\circ} \mathrm{C}$ in different environments.

Figure 9 indicates the EDS results of the samples immersed in different aggressive media (seawater, freshwater, and crude oil) for 28 days. Previous studies have demonstrated that chloride ions can damage the corrosion layer, making it more conducive to corrosion nucleation and development, but the heat treatments of samples are the main reason for decreasing the corrosion rate in different aggressive media.

The particles in EDS results also showed the existing of iron carbon, and oxygen, which suggested that the surface had residues from both the aggressive media and the iron oxide. 

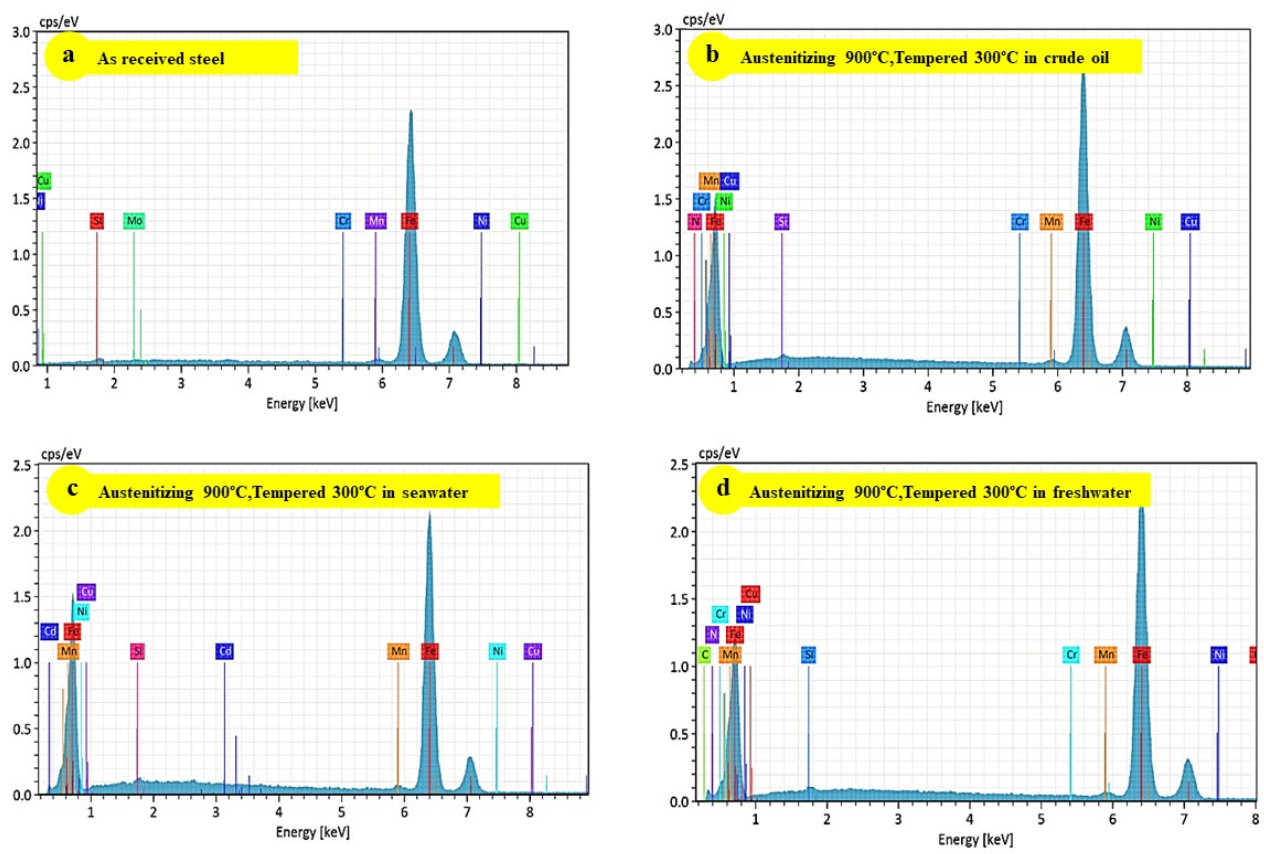

Figure 9. EDS analysis of the samples API X60 steel pipeline immersed in different aggressive media for 28 days.

\section{CONCLUSION}

The influences of heat treatments on the microstructural, mechanical properties, and corrosion rate due to weight loss of API X60 pipeline steel in three different exposing environments were investigated.

- In the as-received metal, the phases that appear in the microstructure examination were ferrite and pearlite, and tempered martensite after austenitizing heat treatment and tempering the predominant phase. The combination of quenching and tempering can improve comprehensive performance.

- The heat treatment application improved the surface protection of $63 \%$ for the specimens in freshwater $\left(900{ }^{\circ} \mathrm{C}\right.$ austenitizing and $300{ }^{\circ} \mathrm{C}$ tempering) compared with $60 \%$ for seawater $\left(900{ }^{\circ} \mathrm{C}\right.$ austenitizing and $300{ }^{\circ} \mathrm{C}$ tempering) and $22 \%$ for crude oil $\left(800^{\circ} \mathrm{C}\right.$ austenitizing and $300{ }^{\circ} \mathrm{C}$ tempering).

- The increase in the impact absorbed energy proportional to tempering temperature that increased to $450{ }^{\circ} \mathrm{C}$. Then, the toughness curve began to fall, where the flake carbides were unevenly distributed on the original martensite boundaries at $600{ }^{\circ} \mathrm{C}$.

- The microhardness of all specimens decreased with increasing tempering temperature; the maximum values were observed at $900{ }^{\circ} \mathrm{C}$ austenitizing tempered at $300{ }^{\circ} \mathrm{C}$ crude oil.

\section{REFERENCES}

Adnan, M Adham, Kok-Eng Kee, Pandian Bothi Raja, Mokhtar Che Ismail, and Saeid Kakooei. 2018. Influence of Heat Treatment on the Corrosion of Carbon Steel in Environment Containing Carbon Dioxide and Acetic Acid. IOP Conf. Ser.: Mater. Sci. Eng. 370: 012039.

Boye, T. E. and O. D. Samuel. 2020. Computer-based method of design and modeling of transient flow in crude oil pipeline system. Journal of Engineering Research 8(3): 219-239. 
ASTM, E3. 2001. Standard practice for preparation of metallographic specimens, Annual Book of ASTM Standards. West Conshohocken, PA, American Society for Testing and Materials.

Chen, Jundan, and Shanping LU. 2012. 'Effects of tempering temperature on the impact toughness of steel 42CrMo'. Acta Metall Sin, 48: 1186-93.

Daramola, OO, BO Adewuyi, and IO Oladele. 2010. Effects of heat treatment on the mechanical properties of rolled medium carbon steel. Journal of Minerals \& Materials Characterization \& Engineering, 9: 693-708.

E407-07, ASTM. 2015. Standard practice for microetching metals and alloys. In.: ASTM International West Conshohocken, PA.

Farelas, Fernando, Yoon-Seok Choi, Srdjan Nesic, Alvaro Augusto O Magalhães, and Cynthia de Azevedo Andrade. 2013. Corrosion behavior of deep-water oil production tubing material under supercritical CO2 environment: Part II. Effect of crude oil and flow. In CORROSION 2013.

Godefroid, Leonardo Barbosa, Betânia Mendes Sena, and Vicente Braz da Trindade Filho. 2017. Evaluation of microstructure and mechanical properties of seamless steel pipes API 5L type obtained by different processes of heat treatments. Materials Research, 20: 514-22.

Hamed, Ibrahim, Magda Mohamed Osman, Omnia Hassan Abdelraheem, and Maher Ibrahim Nessim. 2019. Inhibition of API 5L X52 Pipeline Steel Corrosion in Acidic Medium by Gemini Surfactants: Electrochemical Evaluation and Computational Study, International Journal of Corrosion, 2019: 4857181

Ismail, Noor Mazni, Nurul Aida Amir Khatif, Mohamad Aliff Kamil Awang Kecik, and Mohd Ali Hanafiah Shaharudin. 2016. The effect of heat treatment on the hardness and impact properties of medium carbon steel. IOP Conf. Ser.: Mater. Sci. Eng. 114: 012108.

Ji, Jian Bo, and Jian Tong. 2014. Corrosion rate and mechanical properties of 3161 stainless steel wires in different corrosive conditions. In Applied Mechanics and Materials, 441:48-52.

Jing, Niu, Li-Hua Qi, Ying-Lai Liu, MA Lei, Yao-Rong Feng, and Jian-Xun Zhang. 2009. Tempering microstructure and mechanical properties of pipeline steel X80. Transactions of Nonferrous Metals Society of China, 19: 573-78.

Kuruvila, Roshan, S Thirumalai Kumaran, M Adam Khan, and M Uthayakumar. 2018. A brief review on the erosion-corrosion behavior of engineering materials, Corrosion Reviews, 36: 435-47.

Li, YJ, XL Wang, and YL Zhang. 1993. Corrosion of welded aluminium coated steel in saturated H2S solution, British Corrosion Journal, 28: 149-52.

Liptakova, T., et al. (2014). Mechanical surface treatments effects on corrosion of AISI 316 Ti stainless steel in chloride environments. Journal of Engineering Research 2(3): 1-17.

Ma, Houyi, Xiaoliang Cheng, Guiqiu Li, Shenhao Chen, Zhenlan Quan, Shiyong Zhao, and Lin Niu. 2000. The influence of hydrogen sulfide on corrosion of iron under different conditions. Corrosion science, 42 : 1669-83.

Mohammed Nor, Azmi, Muhammad Firdaus Suhor, Ahmad Zaki Abas, and Sa'adan Mat. 2014. Effect of $\mathrm{CO} 2 / \mathrm{H} 2 \mathrm{~S}$ on corrosion behavior of API 5L 65 carbon steel in high PCO2 environments. In Offshore Technology Conference-Asia. Offshore Technology Conference.

Moosavi, Ali N. 2017. Corrosion in onshore production and transmission sectors - current knowledge and challenges. Trends in Oil and Gas Corrosion Research and Technologies: 95-109.

Pearson, P, and A Cousins. 2016. Assessment of corrosion in amine-based post-combustion capture of carbon dioxide systems. Absorption-based post-combustion capture of carbon dioxide: 439-63. 
Popoola, Lekan Taofeek, Alhaji Shehu Grema, Ganiyu Kayode Latinwo, Babagana Gutti, and Adebori Saheed Balogun. 2013. Corrosion problems during oil and gas production and its mitigation. International Journal of Industrial Chemistry, 4: 1-15.

Rajeev, P, AO Surendranathan, and Ch SN Murthy. 2012. Corrosion mitigation of the oil well steels using organic inhibitors-a review. J. Mater. Environ. Sci, 3: 856-69.

Rustandi, Andi, Nitiyoga Adhika, Tezar Prima, and Nur Aziz. 2013. Behavior of CO2 Corrosion of API 5L X52 Steel in NaCl Solution under Turbulent Flow Condition. In Advanced Materials Research, 476-83.

Rustandi, Andi, Muhammad Adyutatama, Enriko Fadly, and Norman Subekti. 2012. Corrosion rate of carbon steel for flowline and pipeline as transmission pipe in natural gas production with $\mathrm{CO} 2$ content. Makara Journal of Technology, 16: 9.

Sharma, Lochan, and Rahul Chhibber. 2019. Effect of Heat Treatment on Mechanical Properties and Corrosion Behaviour of API X70 Linepipe Steel in Different Environments. Transactions of the Indian Institute of Metals, 72: 93-110.

Souza, Rhuãn C, Luciano R Pereira, Lucas M Starling, José AC Ponciano, and Alysson HS. 2016. The influence of microstructure and heat treatment of API X52 carbon steel on hydrogen diffusion. INTERCORR2016_126

Standard, ASTM. 2004. G31-72, Standard practice for laboratory immersion corrosion testing of metals. West Conshohocken. PA: ASTM International.

Sun, Li, Chuang Li, Chunwei Zhang, Zhongxin Su, and Chen Chen. 2018. Early monitoring of rebar corrosion evolution based on FBG sensor. International Journal of Structural Stability and Dynamics, 18: 1840001.

Swandito, Adji, and Viktor Malau. 2020. Corrosion Rate Analysis of API 5L Gr B Steel Pipe in Acetic Acid Contained Crude Oil Treatment System by Using Amine Base Organik Corrosion Inhibitor. In Materials Science Forum, 191-97.

Tanzi, Maria Cristina, Silvia Farè, and Gabriele Candiani. 2019. Foundations of biomaterials engineering (Academic Press).

Thiangpak, Pakapa, and Aphichart Rodchanarowan. 2018. Effect of post-heat treatment on the mechanical properties of surface-tolerant epoxy coated on API 5L X65 carbon steel pipe: pipeline industry application, Materials Today: Proceedings, 5: 9393-98.

Wang, Zi Ming, and Jian Zhang. 2016. Corrosion of multiphase flow pipelines: the impact of crude oil. Corrosion Reviews, 34: 17-40.

Yadav, M, and Usha Sharma. 2011. Eco-friendly corrosion inhibitors for N80 steel in hydrochloric acid. J. Mater. Environ. Sci, 2: 407-14. 



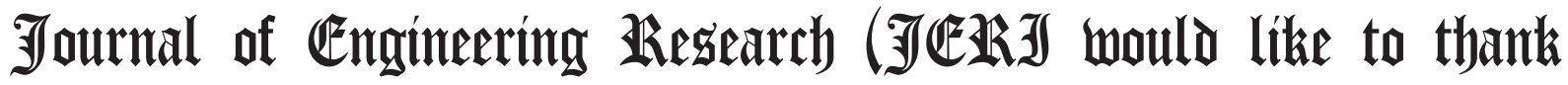
the distinguished indibiduals who put an appreciated effort in refereeing the papers publisted in this issue. Bour valuable time and imput is biathly recoumised by the editorial board of $\mathfrak{J} \mathbb{E}$ R, we look forward to more cooperation in the future to kerp $\mathfrak{J}$ e 